\title{
CHEMICAL COMPOSITION OF THE BARK OF Pinus sibirica
}

\author{
V. V. Grishko, L. I. Demenkova, \\ and V. A. Raldugin
}

UDC 547.595.9

The Siberian stone pine Pinus sibirica R. Mayr - an industrially important coniferous species [1] — has been studied inadequately in the phytochemical respect [2,3]. Continuing an investigation of its isoprenoids [4], we have made a preliminary analysis of the components of the bark extracted by diethyl ether. Of them, only phenolic acids had been identified previously, by GLC.

The extract, obtained with a yield of $5.5 \%$ on the air-dry bark (the raw material was collected from trees with a diameter of $50-60 \mathrm{~cm}$ ), contained $29.4 \%$ of neutral compounds, $8.2 \%$ of strong acids, and $62.4 \%$ of weak acids, which were isolated by the successive treatment of the initial etheral extract with aqueous solution of $\mathrm{NaHCO}_{3}$ and $\mathrm{NaOH}$. The weak acids consisted of resin acids, fatty acids, and polyfunctional acids $(66.9,1.9$, and $31.2 \%$, respectively). The resin acids included lambertianic (42.0\%), abietic (33.1\%), isopimaric (13.9\%), dehydroabietic (6.5\%), and neoabietic (3.4\%) acids (PMR spectrum, $400 \mathrm{MHz}$ ). From the methylated multicomponent polyfunctional acids, by chromatography on $\mathrm{SiO}_{2}$, we isolated the methyl esters of the known [2] 7-ketodehydroabietic and 15-O-methylisocupressic acids.

The strong acids, unlike those of shoots of the Siberian stone pine [4], contained a very small amount of 15-Osuccinylisocupressic acid (about 6\%). After chromatography on $\mathrm{SiO}_{2}$, from PMR spectra and by TLC comparison with authentic specimens, the known $7 \alpha$-hydroxydehydroabietic, 13 $\beta$-hydroxy-7-keto-13,14-dihydroabietic, and 15-hydroxy-7ketodehydroabietic acids were identified in the form of their methyl esters, these in total making up about a third of the weight of all the strong acids.

The neutral part of the initial extract consisted of hydrocarbons $(5.5 \%$, including $3.6 \%$ of diterpenes, $1.7 \%$ of sesquiterpenes, and about $0.2 \%$ of monoterpenes; determined by GLC) a mixture of esters (21.7\%), isocembrol and 4epiisocembrol (16.7\%; ratio 5.3:1, PMR) and polar compounds (48.6\%). By rechromatography of the latter on $\mathrm{SiO}_{2}$, its main isoprenoid components were isolated and identified by their PMR spectra: the labdanoids pinusolide and isoagatholal [2], the triterpenoids 21-episerratenediol and its 21-O-methyl ether [5], and mixtures of stigmast-4-en-3-one and campest-4-en-3-one (16:1, GLC) and of $\beta$-sitosterol and campesterol (17:1, GLC).

The mixture of esters was hydrolyzed, as described in [6]. By chromatography on $\mathrm{SiO}_{2}$, the neutral fraction of the product obtained yielded a mixture of native methyl esters of resin acids (composition the same as that of the methylated mixture of free resin acids from the acid part of the initial extract), aliphatic isoprenoid alcohols (including polyprenols and dolichols, identified provisionally from the results of PMR and HPLC), and a mixture of $\beta$-sitosterol and campesterol.

The investigation of the components of the extract of the bark of the Siberian stone pine is continuing.

\section{REFERENCES}

1. A. S. Isaev, The Pine Forests of Siberia [in Russian], SO "Nauka," Novosibirsk (1985).

2. V. A. Pentegova, Zh. V. Dubovenko, V. A. Raldugin, and É. N. Shmidt, Terpenoids of Coniferous Plants [in Russian], SO "Nauka," Novosibirsk (1987), p. 97.

3. A. S. Gromova, A. I. Syrchina, and N. A. Tyukavkina, Khim. Prir. Soedin., 824 (1971); N. A. Tyukavkina, A. S. Gromova, V. I. Lutskii, and I. S. Chubarova, Khim. Prir. Soedin., 78 (1974).

4. V. V. Grishko, S. A. Shevtsov, L. I. Demenkova, V. A. Raldugin, and G. V. Lyandres, Sib. Khim. Zh., No. 2, 94 (1991).

5. A. H. Conner, V. A. Nagasampagi, and J. W. Rowe, Phytochemistry, 19, 1121 (1980).

6. I. S. Pavlutskaya and V. I. Roshchin, Khim. Drev., No. 3, 102 (1989).

Novosibirsk Institute of Organic Chemistry, Siberian Division of the Russian Academy of Sciences. Translated from Khimiya Prirodnykh Soedinenii, No. 2, pp. 290-291, March-April, 1994. Original article submirted April 12, 1993. 